\title{
SELEÇÃO DE FAMÍLIAS DE FEIJÃO ADAPTADAS ÀS CONDIÇÕES DE INVERNO DO SUL DE MINAS GERAIS' 1
}

\author{
GLAUBER HENRIQUE DE SOUSA NUNES ${ }^{2}$, JOÃO BOSCO DOS SANTOS ${ }^{3}$ \\ MAGNO ANTÔNIO PATTO RAMALHO ${ }^{3}$ e ÂNGELA DE FÁTIMABARBOSAABREU 4
}

\begin{abstract}
RESUMO - O objetivo do trabalho foi selecionar famílias de feijão adaptadas às condições de inverno do sul de Minas Gerais. A partir das populações segregantes L3272 x (Carioca x TU) e L3272 x ESAL 601 foram selecionadas 230 famílias que foram previamente avaliadas no cultivo de inverno no sul de Minas Gerais. Foram mantidas 103 famílias, sendo 79 de ciclo normal e 24 precoces. Esses dois grupos de famílias foram avaliados independentemente, em dois locais, no inverno de 1995. As famílias selecionadas foram avaliadas em um único experimento, no inverno de 1996. Em todos os experimentos foram avaliados os caracteres produtividade de grãos, número de dias para o florescimento, e reação ao patógeno Erysiphe polygoni. Os resultados mostraram heterogeneidade entre as famílias no que tange a todos os caracteres estudados, permitindo a seleção de famílias adaptadas às condições de inverno. A correlação genética entre o número de dias para o florescimento e a reação ao patógeno Erysiphe poligoni foi baixa e negativa. As estimativas das herdabilidades no sentido amplo foram relativamente elevadas quanto a todos os caracteres, nos dois grupos de famílias avaliados. A herdabilidade no sentido amplo, referente a famílias de ciclo normal, foi semelhante à estimativa da herdabilidade realizada.
\end{abstract}

Termos para indexação: Phaseolus vulgaris, cultivo de inverno, tolerância ao frio, precocidade.

\section{SELECTION OF COMMON BEAN FAMILIES ADAPTED TO THE WINTER CONDITIONS OF THE SOUTH OF MINAS GERAIS STATE}

\begin{abstract}
The purpose of the present work was to select common bean families adapted to the winter conditions of South of Minas Gerais State, Brazil. 230 families were selected from segregant populations L3272 $\mathrm{x}$ (Carioca $\times$ TU) and L3272 x ESAL 601. They were evaluated in the winter crops in the South of Minas Gerais, and the 103 most promising ones were selected. The families selected were divided in two sets. The first, with 79 normal cycle families, and the second, with 24 precocious families, which were assessed in two locations, in 1995. The best 24 families were evaluated in the winter of 1996. The traits considered were grain yield, number of the days to flowering and reaction to Erysiphe polygoni. The results showed heterogeneity among families to all traits studied. This heterogeneity allows the selection of families adapted to the winter conditions. The genetic correlation between number of the days to flowering and reaction to Erysiphe polygoni is low and negative. The estimates of heritabilities (broad sense) are relatively high to all traits in the two sets evaluated. The heritability (broad sense) of normal cycle families is similar to realized heritability.
\end{abstract}

Index terms: Phaseolus vulgaris, winter crop, cold tolerance, earliness.

${ }^{1}$ Aceito para publicação em 9 de fevereiro de 1999. Extraído da Dissertação de Mestrado apresentada pelo primeiro autor à Universidade Federal de Lavras (UFLA).

${ }^{2}$ Eng. Agr., M.Sc., Aluno de Pós-graduação da UFLA, Dep. de Biologia, UfLA, Caixa Postal 37, CEP 37200-000 Lavras, MG

${ }^{3}$ Eng. Agr., Dr., Dep. de Biologia, UfLA. E-mail: jbsantos@ufla.br

${ }^{4}$ Enga Agrạ, Dra . ., Embrapa/Epamig, Caixa Postal 37, CEP 37200-000 Lavras, MG. E-mail: afbabreu@ufla.br

\section{INTRODUÇÃO}

Na região sul de Minas Gerais, a cultura do feijão de inverno, instalada entre a segunda quinzena de julho e primeira de agosto, vem se expandindo nos últimos anos, como opção para uma exploração mais eficiente e lucrativa das áreas agrícolas. A evolução dessa cultura no inverno se deve, prin- 
cipalmente, às condições climáticas favoráveis, notadamente temperaturas amenas, menor incidência de pragas e doenças, e a pressão exercida pelo mercado, que eleva o preço do produto e cria expectativas de lucro para os produtores (Silva, 1995).

Uma característica dessa época de cultivo na região é a predominância de temperaturas mínimas em torno de $10^{\circ} \mathrm{C}$ na fase inicial da cultura. Contudo, as cultivares que vêm sendo utilizadas nessa época são adaptadas aos plantios das épocas tradicionais de cultivo (águas e secas). Logo, a maior parte dessas cultivares apresentam sensibilidade à baixa temperatura durante a semeadura. A baixa temperatura contribui principalmente para o atraso na germinação, com conseqüente prolongação do ciclo da cultura em até vinte dias. Esse atraso é prejudicial, porque a colheita coincide com o início das chuvas, tornando-a mais difícil, com redução da produtividade e qualidade do produto. Assim, uma das alternativas para o aumento da produtividade é a busca de cultivares adaptadas às condições de inverno. Outras características desejadas são: porte arbustivo, precocidade, tipo de grão aceitável pelo consumidor e resistência a pragas e doenças, entre elas, a antracnose (Colletotrichum lindemuthianum Sacc \& Magn.) e o oídio (Erysiphe polygoni DC), que ocorrem com grande intensidade no inverno em cultivares suscetíveis.

O objetivo do presente trabalho foi estudar a possibilidade de seleção de famílias adaptadas às condições de cultivo no inverno no sul de Minas Gerais, a partir das populações segregantes L3272 x (Carioca x TU) e L3272 x ESAL 601.

\section{MATERIAL E MÉTODOS}

As populações utilizadas para extração de famílias foram L3272 x (Carioca x TU) e L3272 x ESAL 601. O genitor L3272 é um mutante de sementes bege da cultivar Milionário, que possui sementes pretas, hábito de crescimento tipo II, tolerância ao frio e excelente produtividade de grãos. A linhagem (Carioca x TU), mesmo não sendo adaptada e não possuindo um tipo de grão aceitável pelo mercado consumidor, é de hábito de crescimento I, é precoce, e portadora do alelo Co-5 que confere resistência a um grande número de raças de Colletotrichum lindemuthianum, agente causal da antracnose, principal doença do feijoeiro na região. Por fim, a linhagem
ESAL 601 possui sementes semelhantes ao feijão Carioca, hábito de crescimento II, tolerância às baixas temperaturas na fase jovem da cultura, e é portadora do alelo Co-2, que confere resistência a algumas raças de $C$. lindemuthianum e alta produtividade

A partir dessas duas populações, foram selecionadas 230 plantas individuais com hábito de crescimento arbustivo e com tipo de grão semelhante ao da cultivar Carioca. Cada planta originou uma família $\mathrm{F}_{5}$ que foi avaliada em Lavras, em 1994, no delineamento em blocos aumentados, tendo como tratamentos comuns as cultivares EMGOPA 201-Ouro e Carioca. Foram avaliados os caracteres produtividade de grãos, números de dias para o florescimento ( $50 \%$ das plantas com pelo menos uma flor) e reação ao patógeno Erysiphe polygoni.

Das famílias avaliadas, selecionaram-se $103 \mathrm{~F}_{6}$, sendo 79 de ciclo normal e 24 precoces. As de ciclo normal foram avaliadas em um látice triplo 9x9, incluindo-se como testemunhas as cultivares Carioca e EMGOPA 201-Ouro. As famílias precoces foram avaliadas em um látice triplo 5x5, inclusive a testemunha Rosinha Precoce. Os dois grupos de famílias foram semeados na primeira quinzena de agosto de 1995, em Lavras e Lambari. A parcela foi constituída por duas linhas de dois metros, espaçadas de 0,5 metros. As famílias foram avaliadas pelos mesmos caracteres considerados na geração anterior. Após a avaliação no campo, as 103 famílias $\mathrm{F}_{7}$ receberam inóculo da raça 81 de Colletotrichum lindemuthianum em casa de vegetação. Foram mantidas as 24 mais resistentes aos dois patógenos, com alta produtividade, tipo de grão mais semelhante ao carioca, sendo quatro precoces, e vinte, de ciclo normal. Elas foram avaliadas em Lavras, em um experimento único, no inverno de 1996 , em um látice $5 \times 5$ com três repetições, onde a cultivar Carioca serviu como testemunha. A parcela foi constituída por duas linhas de três metros. As características avaliadas foram produtividade de grãos, dias para o florescimento, e resistência a oídio.

$\mathrm{Na}$ geração $\mathrm{F}_{6}$ estimou-se a herdabilidade no sentido amplo, e o ganho esperado com a seleção nos dois grupos de famílias (normal e precoce). As estimativas das herdabilidades e dos ganhos com a seleção foram feitas conforme metodologia de Vianna \& Silva (1978). A avaliação de 20 famílias de ciclo normal nas gerações $\mathrm{F}_{6}$ e $\mathrm{F}_{7}$ possibilitou a estimativa da herdabilidade realizada, conforme Fehr (1987) e também da eficiência da seleção pelo método de Hamblin \& Zimmermann (1986).

A adubação, a densidade de semeadura e os tratos culturais utilizados nos experimentos foram os normalmente usados na cultura do feijão. A irrigação foi feita por aspersão sempre que necessário. 


\section{RESULTADOS E DISCUSSÃO}

Na execução de um programa de melhoramento voltado para cultivares adaptadas ao cultivo de inverno, no sul de Minas Gerais, é necessário que elas tenham tolerância ao frio na fase inicial da cultura. Dos locais utilizados, Lambari foi o mais favorável para se proceder à seleção, em face das menores temperaturas registradas nos dois primeiros meses dos experimentos (Tabela 1).

$\mathrm{Na}$ avaliação das 230 famílias, não foram observadas diferenças significativas quanto à produtividade de grãos (Tabela 2). O elevado coeficiente de variação, que indicou grandes erros associados às médias, não possibilitou a detecção de heterogeneidade entre as médias das famílias. O alto coeficiente de variação pode ser explicado pelo tamanho pequeno da parcela utilizada $\left(1,0 \mathrm{~m}^{2}\right)$. Normalmente, nos ensaios de avaliação de famílias provenientes de plantas individuais, a quantidade de sementes disponível é pequena, fazendo com que se utilizem tamanhos de parcelas e números de repetições menores, reduzindo-se, conseqüentemente, a precisão experimental. A amplitude de variação foi muito elevada - de 200 a $3.000 \mathrm{~kg} / \mathrm{ha}$-, indicando, assim, a possibilidade de seleção de famílias produtivas (Tabela 2).

A média das famílias foi inferior à média das testemunhas Carioca e EMGOPA 201-Ouro. Contudo, um aspecto importante deve ser ressaltado. Uma vez que as famílias apresentaram diferentes níveis de tolerância ao frio na fase inicial da cultura, as famílias mais sensíveis mostraram um amarelecimento foliar, em virtude da ocorrência de temperaturas abaixo de $10^{\circ} \mathrm{C}$ entre dois e sete dias após a emergência. Em consequiência, essas famílias apresentaram atraso no seu desenvolvimento, o qual refletiu na fase adulta, e, provavelmente, contribuiu para torná-las menos produtivas (Santos \& Ramalho, 1990).

A obtenção de cultivares precoces é importante para reduzir os riscos de a colheita coincidir com o período de chuvas mais intensas, durante o mês de novembro, no sul de Minas Gerais, que pode reduzir a produção e danificar o produto colhido (Ramalho et al., 1993a; Santos et al., 1993). As famílias diferiram quanto ao número de dias para o florescimento. Algumas famílias foram dez dias mais precoces do que as testemunhas; isto indica a possibilidade de seleção de materiais precoces (Tabela 2).

Quanto à reação ao patógeno Erysiphe polygoni, observaram-se diferenças entre as famílias. Além disso, em média, as famílias foram mais suscetíveis do que as testemunhas. Dada a alta suscetibilidade da linhagem (Carioca x TU) e a suscetibilidade mediana da linhagem L3272, era esperada a ocorrência de materiais suscetíveis, elevando a média das famílias. Por outro lado, algumas das famílias apresentaram alto nível de resistência, semelhante à da cultivar Carioca.

Existe grande possibilidade de seleção de famílias precoces e resistentes ao patógeno E. polygoni, graças à variabilidade nos dois caracteres. Entretanto, a correlação entre os caracteres de $-0,22 * *$ (Tabela 2) indica a associação entre a suscetibilidade ao patógeno e a precocidade. Essa associação é relatada na literatura (Araújo et al., 1989; Ramalho

TABELA 1. Número de dias com temperaturas mínimas e suas amplitudes de variação, por local, durante os dois primeiros meses de experimentos.

\begin{tabular}{lccccc}
\hline Local/ano & \multicolumn{9}{c}{ Número de dias abaixo de } & \multicolumn{2}{c}{$\begin{array}{c}\text { Amplitude } \\
\end{array}$} & $6^{\circ} \mathrm{C}$ & $8^{\circ} \mathrm{C}$ & $10^{\circ} \mathrm{C}$ & $12^{\circ} \mathrm{C}$ & $\left({ }^{\circ} \mathrm{C}\right)$ \\
\hline Lavras/1994 & - & 1 & 3 & 23 & 7,9 a 18,4 \\
Lavras/1995 & - & - & 3 & 17 & 8,2 a 15,6 \\
Lavras/1996 & - & 1 & 9 & 10 & 8,3 a 17,4 \\
Lambari/1995 & 14 & 27 & 31 & 55 & 2,6 a 12,8 \\
\hline
\end{tabular}


et al., 1993a). Por outro lado, apesar da significância da correlação, o seu valor foi relativamente baixo, indicando a possibilidade de seleção de famílias que possuam fenótipos desejáveis para os dois caracteres.

A avaliação no inverno de 1994 permitiu a seleção de 79 famílias de ciclo normal e 24 de ciclo precoce. Estas famílias foram avaliadas separadamente, em dois locais. Quanto às famílias de ciclo normal, houve entre elas, diferenças significativas no tocante a todas as características avaliadas (Tabela 3). As famílias, apesar de apresentarem alta produtividade de grãos, não superaram as testemunhas. Com relação ao florescimento, também houve heterogeneidade entre as famílias, mas a média das famílias foi semelhante às médias das cultivares utilizadas como testemunhas. Quanto à reação a E. polygoni, observaram-se diferenças entre as famílias. Contudo a média das famílias foi superior à média da cultivar EMGOPA 201-Ouro, considerada como suscetível ao patógeno. Nas famílias precoces também foi detectada heterogeneidade em todos os caracteres avaliados (Tabela 4). As médias das famílias, no que tange à produtividade de grãos e à reação a $E$. polygoni, foram inferiores às médias da cultivar-testemunha (Rosinha Precoce), enquanto as médias, no que diz respeito ao florescimento, foram próximas.

Os valores das herdabilidades, no sentido amplo, quanto à produtividade de grãos, tanto nas famílias de ciclo normal quanto nas de ciclo precoce (Tabelas 3 e 4), indicam que esse caráter é muito influenciado pelo ambiente. Por outro lado, segundo Santos \& Ramalho (1990), essas magnitudes das herdabilidades, no referido caráter, sugerem a possibilidade de seleção de famílias com maior potencial produtivo. Quanto ao florescimento, as herdabilidades foram altas, o que indica que a maior parte da variância fenotípica é devida a causas genéticas. Esse resultado concorda com os obtidos por outros autores, em que esse caráter é pouco influenciado pelo ambiente (White \& Singh, 1991; Teixeira et al., 1995). Quanto à reação ao patógeno Erysiphe polygoni, as herdabilidades também foram altas, em ambos tipos de famílias (Tabelas 3 e 4). Deve ser ressaltado que a herdabilidade, no sentido amplo, obtida a partir da avaliação de famílias em

TABELA 2. Resumo da análise de variância para a produtividade de grãos $(\mathrm{kg} / \mathrm{ha})$ número de dias para o florescimento, reação a $E$. polygoni ${ }^{1}$ e correlação genética $\left(\mathrm{r}_{\mathrm{g}}\right)$ entre reação a $E$. polygoni e florescimento de famílias $F_{5}$ de feijoeiro. Lavras, MG, 1994.

\begin{tabular}{lrccr}
\hline Fontes de variação & GL & \multicolumn{3}{c}{ Quadrado médio } \\
\cline { 3 - 5 } & & Produtividade & Florescimento & E. polygoni \\
\hline Blocos & 12 & $1.784 .401,72^{* *}$ & $27,86^{* *}$ & $2.128,26 * *$ \\
Famílias (aj.) & 231 & $275.097,87$ & $4,52^{* *}$ & $368,13^{* *}$ \\
Regulares/Bloco & 217 & $203.456,05$ & $4,15^{* *}$ & $316,47^{* *}$ \\
Testemunhas & 1 & $6.286 .777,88^{* *}$ & 2,46 & $378,49 * *$ \\
Test vs. Regul/Bloco & 13 & $1.008 .528,49$ & $10,81 * *$ & $1.270,02 * *$ \\
Erro/bloco & 12 & $5.652,88$ & 0,96 & 9,13 \\
\hline CV (\%) & & 53,07 & 1,69 & 9,11 \\
Média (regulares) & & $1.265,10$ & 57,70 & 30,60 \\
Média (testemunhas) & & $1.944,80$ & 59,90 & 5,70 \\
Família superior & $3.000,00$ & 63,00 & 90,00 \\
Família inferior & 200,00 & 50,00 & 1,80 \\
$\mathrm{r}_{\mathrm{g}}$ & & $0,22 * *$ & \\
\hline
\end{tabular}

${ }^{1}$ Dados transformados em arc sen $(\%)^{1 / 2}$

** Significativo a $1 \%$ de probabilidade pelo teste $\mathrm{F}$ 
TABELA 3. Resumos das análises conjuntas da variância da produtividade de grãos (kg/ha) e número de dias para o florescimento, reação a $E$. polygoni ${ }^{1}$ e estimativas da herdabilidade no sentido amplo e ganho genético em famílias F $_{6}$ de feijoeiro de ciclo normal. Lavras/Lambari, MG, 1995.

\begin{tabular}{|c|c|c|c|c|c|}
\hline \multirow[t]{2}{*}{ Fontes de variação } & \multirow[t]{2}{*}{ GL } & \multicolumn{2}{|c|}{ Quadrado médio (Lavras/Lambari) } & \multicolumn{2}{|c|}{ E. polygoni (Lavras) } \\
\hline & & Produtividade & Florescimento & GL & Quadrado médio \\
\hline Locais (L) & 1 & $5.707 .300,00 * *$ & $1.027,60 * *$ & - & - \\
\hline Famílias (F) & 80 & $232.400,00^{*}$ & $7,40 * *$ & 80 & $245,35 * *$ \\
\hline $\mathrm{F} \times \mathrm{L}$ & 80 & $73.200,00$ & 1,40 & - & - \\
\hline Erro médio & 272 & $155.100,00$ & 1,90 & 136 & 55,11 \\
\hline Média & & $2.046,70$ & 59,90 & & 27,70 \\
\hline Carioca & & $2.238,60$ & 60,70 & & 9,10 \\
\hline E. 201-Ouro & & $2.441,50$ & 59,40 & & 22,00 \\
\hline $\mathrm{CV}(\%)$ & & 19,24 & 2,30 & & 26,80 \\
\hline Efic. látice & & 104,80 & 103,7 & & 168,30 \\
\hline $\mathrm{h}_{\mathrm{a}}^{2}(\%)$ & & 31,00 & 71,90 & & 75,00 \\
\hline$\Delta \mathrm{G}(\%)$ & & 1,80 & 6,50 & & 8,00 \\
\hline
\end{tabular}

${ }^{1}$ Avaliação apenas em Lavras (dados transformados em $\operatorname{arc~sen~}(\%)^{1 / 2}$ ).

$* \mathrm{e}^{* *}$ Significativo, respectivamente, a $5 \%$ e $1 \%$ de probabilidade, pelo teste $\mathrm{F}$.

TABELA 4. Resumo das análises conjuntas da variância da produtividade de grãos (kg/ha), número de dias para o florescimento, resistência a $E$. polygoni ${ }^{1}$, e estimativas da herdabilidade no sentido amplo e ganho genético em famílias $F_{6}$ de feijoeiro de ciclo precoce. Lavras/Lambari, MG, 1995.

\begin{tabular}{|c|c|c|c|c|c|c|}
\hline \multirow[t]{2}{*}{ Fonte de variação } & \multicolumn{2}{|c|}{$\begin{array}{c}\text { Produtividade } \\
\text { (Lavras/Lambari) }\end{array}$} & \multicolumn{2}{|c|}{$\begin{array}{c}\text { Florescimento } \\
\text { (Lavras/Lambari) }\end{array}$} & \multicolumn{2}{|c|}{$\begin{array}{l}\text { E. polygoni } \\
\text { (Lavras) }\end{array}$} \\
\hline & GL & Quadrado médio & GL & Quadrado médio & GL & Quadrado médio \\
\hline Locais (L) & 1 & $3.808 .600,00^{* *}$ & 1 & $115,50 * *$ & - & - \\
\hline Famílias (F) & 24 & $236.800,00^{*}$ & 24 & $3,90 *$ & 24 & $294,20 * *$ \\
\hline $\mathrm{F} \times \mathrm{L}$ & 24 & $105.500,00$ & 24 & 0,60 & - & 57,70 \\
\hline Erro médio & $96^{2}$ & $139.600,00$ & 72 & 1,10 & 36 & \\
\hline Média & & $1.908,00$ & & 56,80 & & 27,70 \\
\hline Rosinha Precoce & & $2.198,80$ & & 55,20 & & 30,80 \\
\hline $\mathrm{CV}(\%)$ & & 19,60 & & 1,90 & & 26,80 \\
\hline $\mathrm{h}_{\mathrm{a}}^{2}$ & & 35,50 & & 73,00 & & 70,00 \\
\hline$\Delta \mathrm{G}(\%)$ & & 2,60 & & 7,50 & & 7,60 \\
\hline Efic. látice & & - & & 114,50 & & 177,60 \\
\hline
\end{tabular}

${ }^{1}$ Avaliação apenas em Lavras (dados transformados em arc sen $(\%)^{1 / 2}$ ).

2 Análise feita em blocos casualizados.

* e ** Significativo, respectivamente, a 5\% e $1 \%$ de probabilidade, pelo teste $\mathrm{F}$ 
estádios avançados de endogamia, pode ser considerada equivalente à herdabilidade no sentido restrito, pois a variância genética total existente entre as famílias é quase toda aditiva, ou seja, a variância que é explorada pela seleção (Ramalho \& Vencovsky, 1978; Souza Júnior, 1989; Ramalho et al., 1993b).

Apesar dos altos valores das herdabilidades em todos os caracteres considerados, como comentado anteriormente, os ganhos com a seleção, em cada caráter, foram pequenos em ambos os grupos (Tabelas $3 \mathrm{e} 4$ ). Isso se deve, provavelmente, ao fato de serem considerados simultaneamente, por ocasião da seleção, vários caracteres como tipo de grão carioca, porte arbustivo e resistência aos patógenos C. lindemuthianum e E. polygoni. Esse resultado evidencia que quando se consideram muitas características ao mesmo tempo, o melhorista tem menores ganhos com a seleção, com relação a cada característica isoladamente. Além disso, a seleção anterior realizada deve ter contribuído para reduzir a variabilidade entre as famílias, e conseqüentemente, reduzido o ganho esperado com a seleção.

As 24 famílias mantidas da geração anterior foram avaliadas em um único experimento, em 1996. As famílias diferiram quanto a todos os caracteres (Tabela 5). A média das famílias referente à produtividade de grãos foi alta, superior à cultivar Carioca. As famílias foram, em média, mais suscetíveis ao patógeno, e mais precoces do que a testemunha. Com relação ao número de dias para o florescimento, a heterogeneidade das famílias era esperada, pois foram avaliados ao mesmo tempo os genótipos precoces e os de ciclo normal. Vale ressaltar que não foi observada antracnose em nenhuma família, a não ser na testemunha Carioca, que é suscetível. Esse resultado era esperado, uma vez que as famílias haviam sido selecionadas em casa de vegetação quanto à resistência à raça 81 de C. lindemuthianum.

Como foram avaliadas 20 famílias de ciclo normal nas gerações $\mathrm{F}_{6}$ e $\mathrm{F}_{7}$, foi possível calcular a herdabilidade realizada e compará-la com a estimada anteriormente à realização da seleção. Os valores da herdabilidade realizada e da herdabilidade no sentido amplo foram semelhantes, a saber: 35,62 e $33,30 \%$, respectivamente. Abreu (1989) e Takeda (1990) também observaram valores semelhantes entre os dois tipos de herdabilidades.

Entre as dez melhores famílias de ciclo normal na geração $F_{6}$, três estiveram entre as melhores em $F_{7}$. Esse resultado ressalta a baixa concordância entre o desempenho médio das famílias nas duas gerações, o que mostra que somente três famílias seriam selecionadas em ambas as gerações (Tabela 6). Utilizando-se a expressão de Hamblin \& Zimmermann (1986), calculou-se a eficiência da seleção com base nas médias de produtividade de grãos da geração

TABELA 5. Resumo das análises de variância referente à produtividade de grãos (kg/ha), número de dias para o florescimento e reação a $E$. polygoni das famílias F $_{7}$ de feijoeiro. Lavras, MG, 1996.

\begin{tabular}{lcccc}
\hline Fontes de variação & \multirow{2}{*}{ GL } & \multicolumn{3}{c}{ Quadrado médio } \\
\cline { 3 - 5 } & & Produtividade & Florescimento & E. polygoni \\
\hline Repetições & 2 & $448.582,12$ & 6,81 & 1,09 \\
Famílias & 24 & $209.078,60^{*}$ & $4,53 * *$ & $2,41^{* *}$ \\
Bloco/repetição & 12 & $191.010,91$ & 1,76 & 0,24 \\
Erro efetivo & 36 & $109.414,06$ & 1,30 & 0,13 \\
\hline Média & & $2.115,12$ & 51,47 & 3,66 \\
Carioca & $2.064,00$ & 58,00 & 1,50 \\
CV (\%) & 15,63 & 2,21 & 9,64 \\
Efic. látice & & 110,46 & 103,47 & 114,86 \\
\hline
\end{tabular}

* e ** Significativo, respectivamente, a 5\% e $1 \%$ de probabilidade, pelo teste $\mathrm{F}$. 
TABELA 6. Produtividade média de grãos, em kg/ha, das 20 famílias de ciclo normal, avaliadas nas gerações $F_{6}$ e $F_{7}$. Lavras, $M G$, 1995/1996.

\begin{tabular}{cccc}
\hline Famílias & $\begin{array}{c}\text { Geração } \\
\mathrm{F}_{6}\end{array}$ & $\begin{array}{c}\text { Geração } \\
\mathrm{F}_{7}\end{array}$ & $\begin{array}{c}\text { Média } \\
\left(\mathrm{F}_{6} \text { e F }\right.\end{array}$ \\
\hline $1^{2}$ & $2.154,00$ & $2.510,00$ & $2.332,00$ \\
$2^{2}$ & $1.522,00$ & $2.452,00$ & $1.987,00$ \\
$3^{3}$ & $2.541,00$ & $2.449,00$ & $2.495,00$ \\
$4^{2}$ & $1.952,00$ & $2.432,00$ & $2.192,00$ \\
$5^{1}$ & $2.547,00$ & $2.429,00$ & $2.488,00$ \\
$6^{3}$ & $2.600,00$ & $2.366,00$ & $2.483,00$ \\
$72^{3}$ & $2.800,00$ & $2.304,00$ & $2.552,00$ \\
$8^{2}$ & $1.576,00$ & $2.276,00$ & $2.714,00$ \\
$9^{2}$ & $1.578,00$ & $2.219,00$ & $1.898,50$ \\
$10^{2}$ & $1.465,00$ & $2.201,00$ & $1.833,00$ \\
$11^{1}$ & $1.542,00$ & $1.200,00$ & $1.371,00$ \\
$12^{1}$ & $1.458,00$ & $2.194,00$ & $1.826,00$ \\
13 & $1.458,00$ & $2.164,00$ & $1.811,00$ \\
$14^{1}$ & $2.580,00$ & $1.123,00$ & $1.851,50$ \\
$15^{1}$ & $2.985,00$ & $2.094,00$ & $2.539,50$ \\
$16^{1}$ & $2.514,00$ & $2.050,00$ & $2.282,00$ \\
$17^{2}$ & $2.561,00$ & $2.031,00$ & $2.296,00$ \\
$18^{1}$ & $2.800,00$ & $1.971,00$ & $2.385,50$ \\
19 & $1.900,00$ & $1.100,00$ & $1.500,00$ \\
20 & $1.580,00$ & $1.045,00$ & $1.312,50$ \\
\hline Média & $2.105,65$ & $2.030,50$ & $2.068,08$ \\
Tukey (5\%) & 986,55 & $1.021,85$ & \\
\hline & & & \\
\hline
\end{tabular}

${ }^{1}$ Família que está entre as dez melhores na geração $\mathrm{F}_{6}$.

${ }^{2}$ Família que está entre as dez melhores na geração $\mathrm{F}_{7}$.

${ }^{3}$ Família que está entre as dez melhores nas gerações $\mathrm{F}_{6}$ e $\mathrm{F}_{7}$

$\mathrm{F}_{6}$, obtendo-se um valor de apenas $22 \%$, em virtude da baixa concordância. Por outro lado, quando a seleção baseou-se na média das duas gerações, a eficiência da seleção aumentou para 55\%. Esse resultado evidencia que o melhor critério para seleção das famílias é a média das gerações. Entre as dez melhores famílias selecionadas na média das gerações $F_{6}$ e $F_{7}$, duas (famílias 8 e 18) são do cruzamento L3272 x (Carioca $\mathrm{x}$ TU) e duas (famílias 15 e 72) do cruzamento L3272 x ESAL 601.

Considerando o tipo de grão semelhante ao da Carioca, produtividade de grãos, porte arbustivo, a resistência ao oídio e à antracnose, foi possível selecionar quatro famílias do cruzamento L3272 x
(Carioca $\mathrm{x}$ TU), sendo duas de ciclo normal e duas precoces, as quais são portadoras do alelo Co-5, e duas do cruzamento L3272 x ESAL 601, de ciclo normal e portadoras do alelo Co-2. Essas famílias poderão ser utilizadas como novas cultivares ou como germoplasma em futuros programas de melhoramento.

\section{CONCLUSÕES}

1. A variabilidade entre famílias quanto à produtividade de grãos, ao número de dias para o florescimento, e à reação ao patógeno Erysiphe polygoni, permite a seleção de famílias adaptadas às condições de inverno do sul de Minas Gerais.

2. As estimativas das herdabilidades no sentido amplo são relativamente elevadas, no que tange a todos os caracteres considerados nos dois grupos de famílias avaliados, e a herdabilidade no sentido amplo, referente a famílias de ciclo normal, é semelhante à estimativa da herdabilidade realizada.

3. Existe correlação genética pequena e negativa entre o número de dias para o florescimento e a reação ao patógeno Erysiphe poligoni.

\section{REFERÊNCIAS}

ABREU, A. de F.B. Avaliação de progênies do cruzamento "Carioca 80" $x$ "Rio Tibagi" em diferentes densidades de plantio. Lavras: ESAL, 1989. 63p. Dissertação de Mestrado.

ARAÚJO, G.A. de A.; VIEIRA, C.; COSTA, C.R.; OLIVEIRA, F. de; LIMA, C.A.J.; VIEIRA, R.F.; CHAGAS, J.M. Comportamento de cultivares precoces de feijão (Phaseolus vulgaris L.) no Estado de Minas Gerais. Revista Ceres, Viçosa, v.36, n.203, p.106-114,jan./fev. 1989.

FEHR, W.R. Principles of cultivar development: theory and technique. New York: MacMillan, 1987. 525p.

HAMBLIN, J.; ZIMMERMANN, M.J. de O. Breeding common bean for yield in mixtures. Plant Breeding Reviews, Connecticut, v.4, p.245-272, 1986.

RAMALHO, M.A.P.; ABREU, A. de F.B.; SANTOS, J.B. dos. Desempenho de famílias precoces de feijoeiro em diferentes locais e épocas de plantio. Revista Ceres, Viçosa, v.40, n.229, p.272-280, maio/jun. 1993a. 
RAMALHO, M.A.P.; SANTOS, J.B. dos; ZIMMERMANN, M.J. Genética quantitativa em plantas autógamas. Goiânia: UFG, 1993b. 271p.

RAMALHO, M.A.P; VENCOVSKY, R. Estimação dos componentes da variância genética em plantas autógamas. Ciência e Prática, Lavras, v.2, n.2, p.117-140, jul./dez. 1978.

SANTOS, J.B. dos; RAMALHO, M.A.P.; ABREU, A de F.B. Seleção de progênies de feijoeiro na população Rio Tibagi x ESAL 501 adaptadas às condições de inverno do sul de Minas Gerais. Pesquisa Agropecuária Brasileira, Brasília, v.28, n.4, p.509513, abr. 1993.

SANTOS, J.B. dos; RAMALHO, M.A.P. Seleção de progênies de feijoeiro adaptadas às condições de outono e inverno no sul de Minas Gerais. Pesquisa Agropecuária Brasileira, Brasília, v.25, n.11, p.1655-1661, nov. 1990.

SILVA, O.F. da. O feijão de inverno: aspectos econômi$\cos$ da cultura em Goiás. Goiânia: Embrapa-CNPAFAPA, 1995. 32p. (Embrapa-CNPAF. Documentos, 57)
SOUZA JÚNIOR, C.L. de. Componentes da variância genética e suas implicações no melhoramento vegetal. Piracicaba: FEALQ, 1989. 134p.

TAKEDA, C. Avaliação de progênies de feijoeiro do cruzamento 'Esal 501' $x$ 'A354' em diferentes ambientes. Lavras: ESAL, 1990. 82p. Dissertação de Mestrado.

TEIXEIRA, F.F.; RAMALHO, M.A.P.; ABREU, A. de F.B. Estimativa do número de genes envolvidos no controle da floração do feijoeiro usando a metodologia de Jinks \& Towey. Ciência e Prática, Lavras, v.19, n.3, p.335-338, jul./set. 1995.

VIANNA, R.T.; SILVA, J.C. Comparação de três métodos estatísticos de análises de variância em experimentos em "látice" em milho (Zea mays L.). Experientiae, Viçosa, v.24, n.2, p.21-41, fev. 1978.

WHITE, J.W.; SINGH, S.P. Sources and inheritance of earliness in tropically adapted indeterminate common bean. Euphytica, Wageningen, v.55, n.1, p.15-19, May 1991 